\title{
Adolescent Girls Empowerment Programme: Endline technical report
}

\author{
Karen Austrian \\ Population Council \\ Erica Soler-Hampejsek \\ Paul C. Hewett \\ Population Council \\ Natalie Jackson Hachonda \\ Population Council
}

Jere R. Behrman

Follow this and additional works at: https://knowledgecommons.popcouncil.org/departments_sbsr-pgy

Part of the Demography, Population, and Ecology Commons, Family, Life Course, and Society Commons, Gender and Sexuality Commons, and the International Public Health Commons How does access to this work benefit you? Let us know!

\section{Recommended Citation}

Austrian, Karen, Erica Soler-Hampejsek, Paul C. Hewett, Natalie Jackson Hachonda, and Jere R. Behrman. 2018. "Adolescent Girls Empowerment Programme: Endline technical report." Lusaka: Population Council. 


\section{ADOLESCENT GIRLS EMPOWERMENT PROGRAMME ENDLINE TECHNICAL REPORT}

\section{DECEMBER 2018}

\section{Authors}

\section{Karen Austrian, PhD, MPH}

Senior Associate

Population Council, Kenya

\section{Erica Soler-Hampejsek, PhD}

Independent Consultant

Spain

Paul C. Hewett, PhD

Senior Associate

Population Council, USA

\section{Natalie Jackson Hachonda}

Senior Programme Officer

Population Council, Zambia

Jere R. Behrman, PhD

Professor of Economics

University of Pennsylvania 
The Population Council confronts critical health and development issues-from stopping the spread of HIV to improving reproductive health and ensuring that young people lead full and productive lives. Through biomedical, social science, and public health research in 50 countries, we work with our partners to deliver solutions that lead to more effective policies, programs, and technologies that improve lives around the world. Established in 1952 and headquartered in New York, the Council is a nongovernmental, nonprofit organization governed by an international board of trustees.

\section{Population Council, Zambia}

Plot 3670, No. 4

Mwaleshi Road, Olympia Park

Lusaka, Zambia

Tel: +260211295925

email: info.zambia@popcouncil.org

(C) 2018 The Population Council, Inc.

Suggested citation: Austrian, Karen, Erica Soler-Hampejsek, Paul C. Hewett, Natalie Jackson Hachonda, and Jere R. Behrman. 2018. Adolescent Girls Empowerment Programme: Endline Technical Report. Lusaka, Zambia: Population Council.

For more information about the design of AGEP and the evaluation, please refer to the following:

Hewett, Paul C., Karen Austrian, Erica Soler-Hampejsek, Jere R. Behrman, Christine A. Kelly, Dela Kusi-Appouh, Fiammetta Bozzani, Barbara S. Mensch, and Minyoi Maimbolwa. 2014. Adolescent Girls Empowerment Programme: Research and Evaluation Baseline Technical Report. Lusaka, Zambia: Population Council.

Hewett, Paul C. Karen Austrian, Erica Soler-Hampejsek, Jere R. Behrman, Fiammetta Bozzani, and Natalie A. Jackson-Hachonda. 2017. Cluster randomized evaluation of Adolescent Girls Empowerment Programme (AGEP): study protocol. BMC Public Health: 17:386. DOI 10.1186/s12889-017-4280-1. 


\section{Table of Contents}

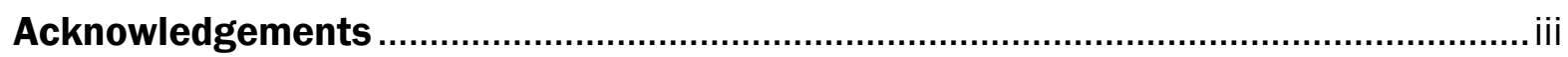

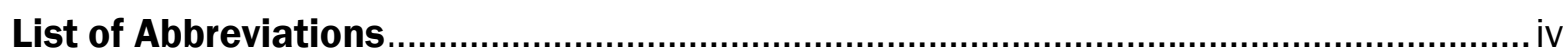

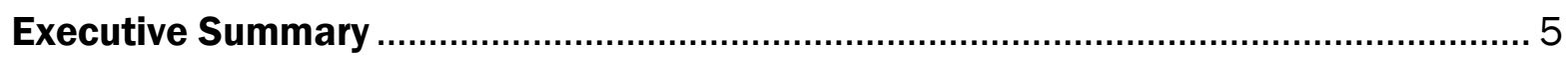

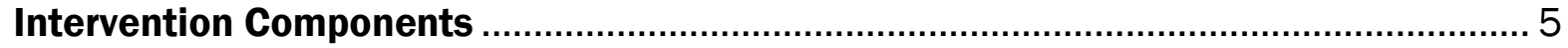

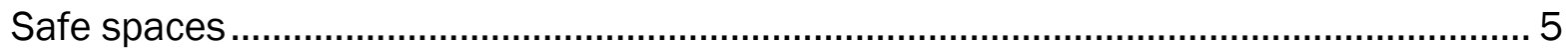

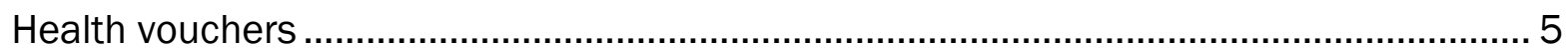

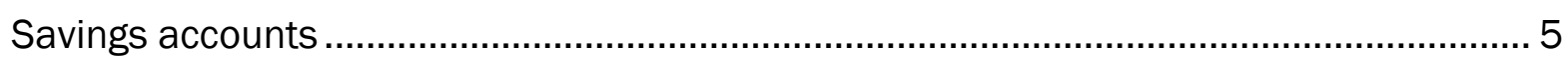

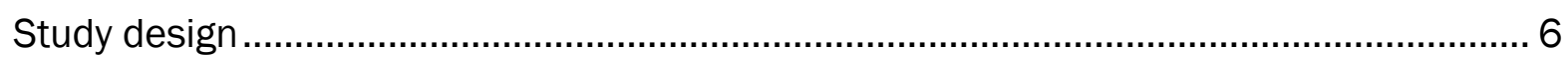

AGEP impact on social, health, and economic assets ……........................................ 6

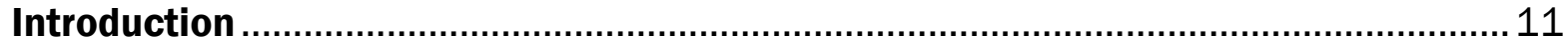

Adolescent girls in Zambia ………......................................................................... 11

Adolescent Girls Empowerment Programme - Intervention Summary ........................13

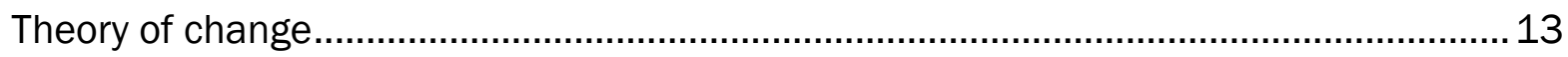

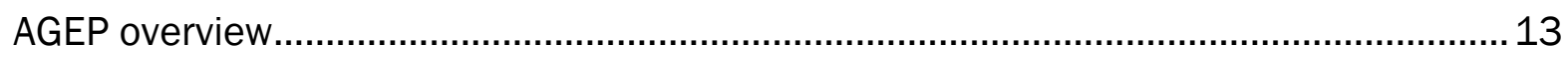

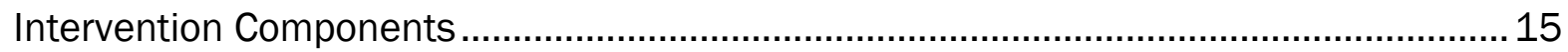

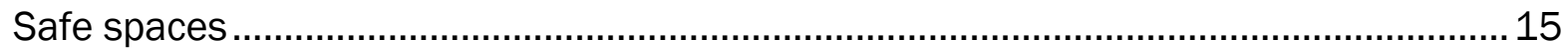

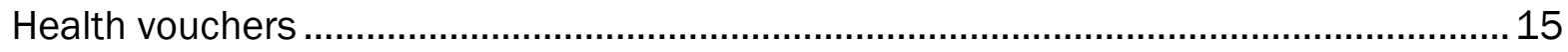

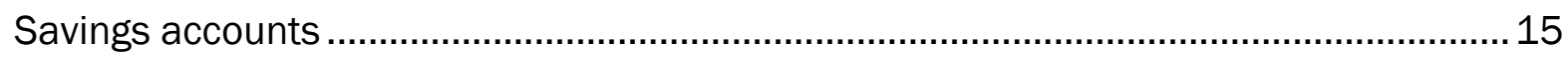

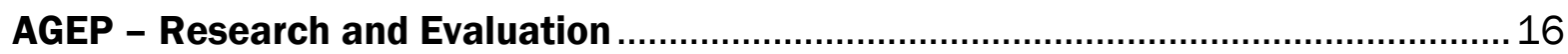

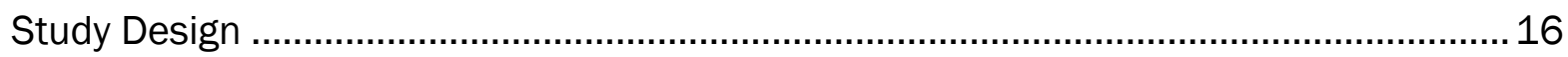

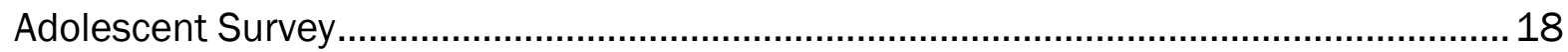

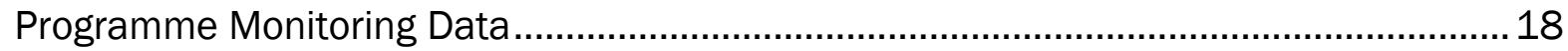

Statistical Analysis and Evaluation Assessment......................................................18

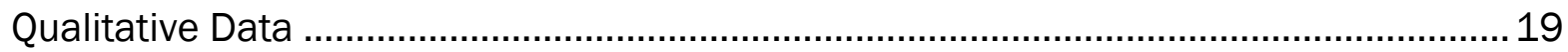

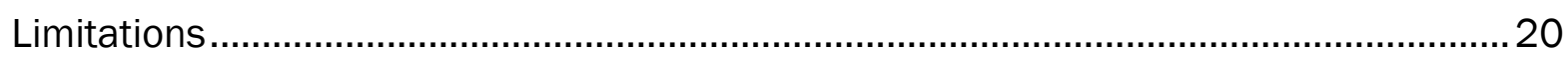

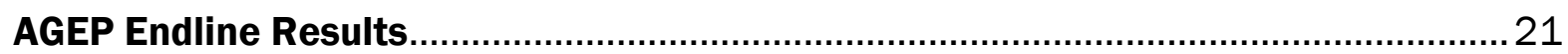

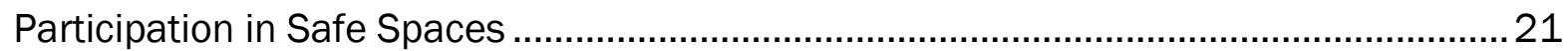

AGEP Mid- and Long-Term Impact on Social, Health, and Economic Assets....................22

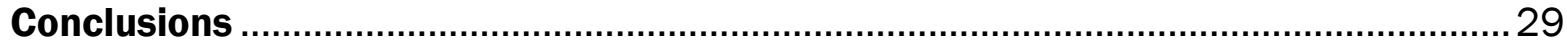

Annex A: List of Safe Spaces Training Session Topics ………………………............33

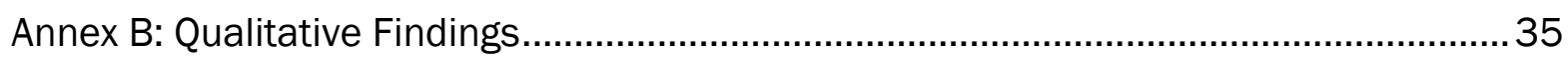

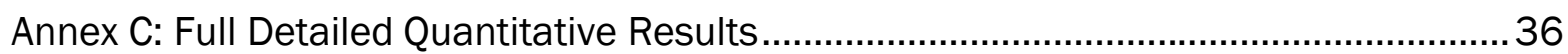




\section{Acknowledgements}

This endline report would not be possible without the hard work of diverse programme and research teams dedicated to improving the lives of vulnerable adolescent girls.

At the Population Council: the AGEP implementation team, including Chipo Zulu, Nambula Kachumi, Bwalya Mushiki, Misozi Siwela, Pamela Nyirenda, and Diana Bulanda, as well as all of the site coordinators, who successfully implemented an expansive and complex intervention and helped to prepare the communities for research activities as well. We thank Chama Mapulanga, Kevin Kapungu, and Mary Namukoko who served as study coordinators; Dominic Nzala and Paul Banda who served as fieldwork coordinators; Minyoi Maimbolwa who served as data manager; Oscar Mbulwe and Jerrix Nkhata who supervised the biomarker collection; Rogers Musonda who served as the study cartographer; Memoona Malik who supervised the anthropometric measurement; and the entire group of team leaders and research assistants who spent so much of their time in the field collecting data. We would also like to acknowledge the efforts of the finance and administrative team at Population Council Zambia, including Masida Chisambi, Swedish Sianyaka, Khukhie Makukisi, and Memory Sichizuwe. Additional thanks to Samir Souidi and Stan Mierzwa at the Population Council headquarters for the development of the tablet-based electronic data capture tools.

Many thanks to Jessica DeMulder at the Population Council and John Maluccio at Middlebury College for feedback on preliminary versions of the analysis and report and to Christina Tse and her team for editing and layout.

We also thank the Ministry of Health and the Ministry of Community Development and Social Services for their support of AGEP overall, and the research specifically.

At the YWCA Zambia, we would like to acknowledge the efforts of Bernard Munkombwe, Debbie Chingobe Kangombe, and all the site coordinators who were also instrumental in the preparation and implementation of research and programme activities at the field level.

The authors thank the UK Department for International Development (DFID) and those from DFID and the Evidence Scrutiny Committee who provided feedback on the draft report. We especially thank Valerie Roberts, Clare McCrum, and Florence Mabandhla at DFID for their support and guidance through the life of AGEP. DFID's investment in rigorous research will benefit not only Zambia, but the field of adolescent girls programming as a whole.

Finally, we are grateful to the adolescent girls who shared their thoughts and experiences with us and thank them for participating in both the programme and the research. 


\section{List of Abbreviations}

ACAS

Audio Computer-Assisted Self-Interviewing

AGEP

Adolescent Girls Empowerment Programme

ATE

Average Treatment Effects

CAPI

Computer-Assisted Personal Interviewing

CSA

Census Supervisory Area

CSO Central Statistical Office

$\mathrm{DCHO}$

District Community Health Office

DHS

Demographic and Health Survey

DID

Difference in Differences

GBV/SGBV

Gender-Based Violence/Sexual and Gender-Based Violence

HIV

Human Immunodeficiency Virus

HSV-2

Herpes Simplex Virus - type 2

IPV

Intimate Partner Violence

ITT

Intent to Treat

IV

Instrumental Variable

MCDMCH Ministry of Community Development, Mother and Child Health

MCDSW Ministry of Community Development and Social Welfare

$\mathrm{MOH}$

Ministry of Health

Natsave

National Savings and Credit Bank

ODK

Open Data Kit

PSM

Propensity Score Matching

RCD Randomised Cluster Design

SRH Sexual and Reproductive Health

STI Sexually Transmitted Infection

ToT

Treatment on Treated

UNZA-BREC University of Zambia, Biomedical Research Ethics Committee YWCA Young Women's Christian Association 


\section{Executive Summary}

\section{Introduction}

Adolescent girls in Zambia face a range of risks and vulnerabilities that challenge their healthy development from girls into young women, and they often lack the social, health, and economic assets that are necessary to mitigate these risks. The issues that confront vulnerable girls high rates of gender-based violence, unsafe sex that puts girls at risk for unwanted pregnancies and HIV infections, school dropout, lack of economic resources and income-generating options, and lack of agency and participation - are interdependent and have similar causes.

The situation is a challenging one for adolescent girls in Zambia. Across a wide range of issues-education, social support, safety, and sexual and reproductive health-girls are at a greater disadvantage compared to their male peers. The vulnerabilities confronting Zambian adolescent girls formed the basis for designing the Adolescent Girls Empowerment Programme (AGEP), which a) focused on adolescent girls aged 10-19, b) delivered community-based interventions and c) selected participants for the programme with the direct intention of capturing those girls who were the most vulnerable. AGEP was rolled out in 10 sites in four provinces in Zambia, five sites in urban areas, and five sites in rural areas, and aimed to reach 1,000 girls per site, for a total of 10,000 girls in the programme.

The theory of change behind AGEP posited that adolescent girls are empowered by building their social, health, and economic assets that they can then draw on to reduce vulnerabilities and expand opportunities. In the long term, they will then increase their likelihood of completing school, delaying sexual debut, and reducing risks of early marriages, unintended pregnancies, acquisition of HIV, and other possibly detrimental outcomes.

\section{Intervention Components}

Safe spaces: Safe spaces were weekly girls' group meetings, implemented in partnership with YWCA Zambia, in which 20 to 30 girls met with a mentor-a young woman from their community who was hired and trained-for short training sessions on a variety of topics as well as an opportunity to discuss together their experiences in the past week. AGEP developed three curricula for adolescent girls that were used in the safe space meetings: 1) a health and lifeskills curriculum, 2) a financial education curriculum, and 3) a nutrition curriculum.

Health vouchers: In partnership with the Ministry of Community Development, Mother and Child Health $(\mathrm{MCDMCH})$, participants received a health voucher redeemable for a package of general wellness and sexual and reproductive health services at partner public and private healthcare providers. For private and NGO providers, payment was made on a "fee-for-service" basis with pre-approved reimbursement rates, whereas for the public facilities, incentives for each service were paid to the District Community Health Offices (DCHO) and then distributed among the district health offices and the clinics in previously agreed-upon percentages.

Savings accounts: The Population Council worked in partnership with the National Savings and Credit Bank (Natsave) and Making Cents International to develop the Girls Dream savings 
accounts for AGEP girls. The Natsave accounts had very low minimum opening balances of ZMW 2.5 (US \$0.50) and any amount could be deposited or withdrawn with no fee.

\section{Study design}

A randomised cluster design was implemented to rigorously assess the impact of AGEP, as well as the impact of each of its core components, on the trajectories of girls' lives in their adolescent years and into early adulthood. In order to assess the effect of the safe spaces alone, as well as the added effect of the health voucher and savings account, AGEP was implemented in three versions across randomised study arms: Arm 1 included safe spaces only; Arm 2 included safe spaces and the health voucher; and Arm 3 included safe spaces, the health voucher, and the savings account. Arm 4 was a control group that received no intervention.

\section{Key Findings}

The AGEP endline evaluation focused on three main questions: 1) whether or not the changes in social, health, and economic assets (which are the mediating factors) that were observed at midline were sustained; 2) were there new impacts observed in the social, health, and economic asset indicators and 3 ) did the intervention result in any longer-term change on demographic, reproductive, and health outcomes, and if so, for which girls.

\section{AGEP impact on social, health, and economic assets}

Social assets: In the evaluation of AGEP, two key measures of empowerment via social assetbuilding were measured-social safety nets and self-efficacy. At midline-which measured the impact immediately at the completion of the two-year intervention-girls in the three intervention arms were more likely than girls in the control arm to have a place in the community where they could meet other girls their age apart from their home and school. However, there were no effects on self-efficacy. Two years post-programme, there was no longer a difference between programme and control arm girls vis-à-vis social safety nets, suggesting that the public spaces within communities that were created for girls by the programme were no longer available to them. However, with self-efficacy, an endline effect did appear. One potential explanation for this latent effect is that as girls grew older, the depth of life experiences in which they could apply the learnings and skills built from AGEP increased (especially for those with savings accounts), and therefore their beliefs in their abilities were concretised and became measurable.

Gender norms and acceptability of spousal violence: At the midline evaluation there was no effect of AGEP on either gender norms-which measured adolescent girls' attitudes on gender roles in adolescence-or acceptability of intimate partner violence (IPV) as measured by five items asking if it was acceptable for a husband to beat his wife in certain scenarios. The twoyear follow-up showed that these norms and attitudes remained unchanged and there were no differences between AGEP and control arms.

Health assets: The two main health assets measured in the AGEP evaluation were sexual and reproductive health $(\mathrm{SRH})$ knowledge and HIV knowledge. At midline there was an increase in $\mathrm{SRH}$ knowledge among girls in the programme arms relative to girls in the control, however there was no difference in the increase in HIV knowledge between the two groups. At endline, the AGEP girls continued to have higher levels of SRH knowledge compared to the control girls. 
However, it should be noted that overall, SRH knowledge was very low at baseline, and while it increased over the four years, it remained low at endline. Specifically, SRH knowledge approximated the equivalent of girls learning about two new methods of contraception over that period, indicating room for further education on these topics.

Economic assets: The two main economic asset indicators measured were financial literacy and savings behaviour in the past year. At midline, AGEP had a positive increase on financial literacy for all girls in the programme arms, but at endline, the overall effect on financial literacy for all programme arms no longer remained. Regarding savings behaviour, a positive effect on savings activity at midline was present and that effect remained at endline.

\section{AGEP impact on demographic, reproductive, and health outcomes}

Experience of violence: Overall, neither at midline nor at endline, did the AGEP intervention have an effect on girls' experience of physical or sexual violence. Important to note, however, is that experience of both kinds of violence was high at baseline, and steadily increased over the course of the study such that by ages 14-23 two-thirds of girls had experienced physical violence and by ages 15-23 half of girls had experienced sexual violence.

Sexual behaviour: Overall, the AGEP intervention had little impact on either overall sexual activity or sexual behaviour among those who were sexually active-at both midline and endline. This included contraceptive use, condom use, and number of sexual partners. At midline, girls who were sexually active at baseline were more likely to use a condom, but by endline that effect was no longer present. This means that in the longer term, the AGEP programme did not have a positive influence on girls' safer sex behaviours. The one area of positive impact was that girls were less likely to have had transactional sex, and this effect was present at midline and at endline.

Pregnancy and marriage: Counter to the initial hypothesis, participation in AGEP did not delay the timing of pregnancies or marriages for girls in the programme arms. Overall, 39\% of girls had given birth by the end of the two-year follow-up period and $28 \%$ of girls were married or living with their partner-and there was no significant difference between the programme and control arms.

Overall, in reflecting back on the theory of change, the hypothesis was that the AGEP interventions would lead to increased social, health, and economic assets, and those in turn would lead to longer-term education, fertility, and health improvements. The theory of change did not prove to be confirmed in two major elements: 1) there was positive change only on a subset of the mediating factors-largely the economic assets and some of the health assets, but not on most social assets-and with modest effect sizes; and 2) the changes that did take place in the mediating outcomes were not sufficient to lead to longer-term change. Therefore, overall, the pathways to change that were anticipated did not take place.

\section{Conclusions}

At the end of the two-year programme (the midline), the following impacts were observed:

- Improved sexual and reproductive health knowledge

- Improved access to safe spaces in the community 
- Improved financial literacy

- Improved savings behaviours

- Decreased transactional sex (for girls who were sexually active at the start)

Two years after the end of the programme (the endline), the following impacts were seen:

- Improved sexual and reproductive health knowledge

- Improved self-efficacy

- Improved savings behaviours

- Decreased transactional sex (for girls who were sexually active at the start)

There were no medium or long-term effects on:

- Pregnancy/birth

- Marriage

- Sexual debut, contraceptive use, condom use, multiple sexual partners

- Equitable gender attitudes

- Experience of physical or sexual violence

Therefore, while there were some changes for the programme participants in the medium and long term, they did not translate into longer-term effects on reproductive and demographic outcomes as hypothesised via the theory of change. However, interpretation of these results is constrained by two important factors: a) a large proportion of the girls invited to the programme did not participate, and b) among those who did participate, only a sub-segment of them participated actively in the safe-spaces sessions. Knowing both who is and is not participating in a programme meant to target vulnerable adolescent girls is important-for programmatic implementation guidance as well as interpretation of results.

One of the clearest and most consistent findings was in the economic asset-building component. The savings account catalysed positive savings behaviour-both formal and informal-and had positive effects on girls' self-efficacy. This provides an indication to programmes working with adolescent girls as to the feasibility and important impact of integrating financial literacy training and access to savings opportunities into more traditional health-related programming.

\section{Recommendations for policymakers/implementers:}

1) The most vulnerable adolescent girls will likely not attend a safe spaces-only programme. While the safe spaces platform to building assets for girls can be leveraged to achieve longer-term change for girls on a range of well-being outcomes, it is likely that the most vulnerable are going to participate less, or not at all, as there are too many barriers to their participation. Programme implementers must ensure that they have the systems and budgets in place to track who is, and is not, participating. In order for programmes to be successful, they will need to include adaptations that address the needs of those sub-segments of the population (e.g., out of school, economically most disadvantaged, those living apart from their parents) to allow for enrolment and active participation. 
2) Acceptability and experience of sexual and gender-based violence (SGBV) among adolescent girls and young women in Zambia is alarmingly high; it will take a more holistic, community-level programme to address this. Sixty percent of girls think that violence is acceptable in certain circumstances and over half of girls ages 14-23 have already experienced sexual violence. Given that the AGEP intervention components all worked at the level of the girls and had no impact on either of these sets of indicators, future programmes that aim to reduce SGBV among adolescents should address inequitable attitudes and norms not only with adolescent girls directly, but around addressing violence at the household, school, and community levels, as well.

3) Economic barriers will negatively influence adolescent programmes - even those that are health-oriented-and need to be addressed in adolescent programming. Household economic barriers exist, especially among the most vulnerable, that will both prevent participation, as well as prevent desired health outcomes from being achieved.

Programmes should consider education support to those who are at risk of schooldropout or are out-of-school but likely to return to school. Social cash transfers may have the potential to alleviate some of the economic stress of the household, freeing up girls to participate in programmes. It may also mitigate some of the economic reasons that drive transactional sex, school dropout, and/or early marriage. Individual economic barriers, especially for older girls, also exist. Retaining an economic component to the programme, financial literacy and savings, will help address these issues. For older girls, it is likely that additional activities that promote income-generation will need to be added to programmes.

\section{Recommendations for donors/researchers:}

1) More analysis can be done with the AGEP data set. There is a wealth of data available that can be used to look at the impact of the programme on additional outcomes and for various subsets of the adolescent girls cohort. The data are available at the Adolescent Data Hub. 1

2) Many evidence gaps remain, and as this is a complex issue with multiple interdependent outcomes, more research is needed. More work should be done to deliver and evaluate programmes that aim to address long-term health outcomes for adolescents, that take a multi-level approach including simultaneous work with communities, households, and adolescents themselves.

3) More funding for longitudinal research on adolescents is needed. The results between midline and endline did change-including some emerging results-and therefore there is value in following cohorts of adolescents through to early adulthood to understand the effect of interventions in early and mid-adolescence on later adolescence and early adulthood. This may include effects on the transition to the workforce, quality of marital relationships, health and education outcomes for adolescents' children, etc. Additional longitudinal research, that combines data from these different levels, will help to understand the multiple factors and context that shapes adolescent transitions into adulthood. 
4) More research and learning from work on cash transfers are needed. More research is needed in Zambia to evaluate programmes that combine asset-building for adolescents with cash incentives at the household level. There is promising evidence coming out of Kenya $^{2}$ that suggests that there may be long-term success when these are combined and implemented in early adolescence. In addition, The Transfer Project has been conducting work in Zambia, ${ }^{3}$ and other countries in sub-Saharan Africa, ${ }^{4}$ that could provide useful insights on the role of social protection cash transfer programmes. The potential of combining general cash transfers with additional programming for adolescents remains a promising area that needs more research.

The AGEP evaluation is an important contribution to the understanding of adolescent transitions and interventions in Zambia. The rigorous and long-term approach provides a level of certainty, attribution, and conclusions that are unparalleled in Zambia. It is our hope that this evaluation will contribute to the improvement of current programmes, as well as development of new programmes and funding strategies. The data show that early pregnancy, violence, and HIV are still very pressing issues for adolescents in Zambia and evidence should be used to design and implement the programmes most likely to improve adolescent girls' lives going forward.

\footnotetext{
${ }^{2}$ https://www.popcouncil.org/uploads/pdfs/2018PGY AGI-K MidlineReport.pdf

3 https://transfer.cpc.unc.edu/countries-2/zambia/

4 https://transfer.cpc.unc.edu/countries-2/
} 


\section{Introduction}

\section{Adolescent girls in Zambia}

Adolescent girls 5 in Zambia face a range of risks and vulnerabilities that challenge their healthy development from girls into young women, and they often lack the social, health, and economic assets to mitigate these risks. The issues that confront vulnerable girls-high rates of genderbased violence, unsafe sex that puts girls at risk for unwanted pregnancies and HIV infections, school dropout, lack of economic resources and income-generating options, lack of agency and participation-are interdependent and have similar causes.

Child marriage: Married adolescents have limited social, health, and economic assets. Child brides often experience a sudden shrinking of their social networks as they move to their husbands' residences, leaving them with few, if any, friends and peers. While parents may want their daughters to marry at an early age for perceived economic stability, anticipating that the new husbands will cater to the needs of the girls, in reality, child marriage often leaves girls with limited control over resources, restricted mobility, and little or no power in their new households. ${ }^{6}$ Thus, married girls may face significant challenges in negotiating safe sexual relations. In Zambia, according to the 2013-14 DHS, 7 7\% of girls aged 15-17 were currently married and $2 \%$ of girls had been married by age 15 . Among $20-24$-year-old females, $6 \%$ were married by age $15-19$ and $31 \%$ by age 18 . Girls living in this context are vulnerable, sexually active, with a unique set of needs, and are often missed by general youth programmes, as well as by general sexual and reproductive health programmes intended for women.

Education: It is known that education is a critical component of a healthy transition to adulthood. For example, being in school has been associated with delays in the age at first sex, marriage, and childbearing. However, in both rural and urban settings in Zambia, $41 \%$ of girls ages 10-14 are already off-course with their schooling - meaning that they have either never attended primary school, are not currently in school, or are in school but are two or more years behind grade-for-age. When comparing girls' and boys' non-enrolment, levels are similar for the 10-14-year-old group (approximately 10\%), but the gender disparity is clear among older adolescents with $44 \%$ of girls aged $15-19$ not in school as compared to $31.1 \%$ of boys. In other words, girls leave school at significantly higher rates than boys. Interventions that are schoolbased may, therefore, miss large segments of the adolescent girl population-often including those who are most vulnerable.

Gender-based violence (GBV): Lack of social protection and voice leaves girls exposed to violence, both physical and sexual. More than 35\% of 15-24-year-old females have experienced physical violence, and $12 \%$ have already experienced sexual violence. A study by the Population Council ${ }^{8}$ among girls aged 15-24 in urban slums in Lusaka found pervasive levels of violence for adolescent girls at home and in the community. School, a place supposed to be protective, is not necessarily safe for girls. Seventy percent of girls in that study reported having been teased or sexually harassed in school and 53\% reported that girls in their school

\footnotetext{
${ }^{5}$ For this document, adolescent girls are defined as girls ages 10-19.

6 Erulkar, A. 2013. "Adolescence lost: The realities of child marriage," Journal of Adolescent Health 52(5): 513-514.

7 In this Introduction section, except in the case of sources otherwise noted, the data discussed come from the 2013-2014 Zambia Demographic and Health Survey report or data analysis conducted. Central Statistical Office (CSO) [Zambia], Ministry of Health (MOH) [Zambia], and ICF International. 2014. Zambia Demographic and Health Survey 2013--14. Rockville, MD: Central Statistical Office, Ministry of Health, and ICF International.

8 Brady, Martha et. al. 2009. Understanding Adolescent Girls' Protection Strategies Against HIV: An Exploratory Study in Zambia. New York: Population Council.
} 
were molested. Eighty-six percent reported that girls their age were pressured to do things they did not want to do in exchange for money. These issues go beyond experience of violence, to include acceptance of it. Data from the 2013-14 DHS confirm that in Zambia harmful gender norms are formed by an early age. Among 15-24-year-old females, 48\% believe that wife beating is justified in at least one circumstance. Therefore, it is critical to reach girls early, addressing gender norms and rights, in an effort to reduce violence against girls.

HIV and other health risks: HIV is a significant health risk to girls in Zambia. The threat is particularly acute among young women and girls with limited social and economic assets who are unable to avoid, manage, or leave unsafe sexual relationships, whether inside or outside of marriage. ${ }^{9}$ In Zambia, the 2014 DHS indicates that HIV prevalence is 15\% for females and $11 \%$ for males. Among 15-19-year-olds, $5 \%$ of females are infected as compared to $4 \%$ of males. The gender disparity increases in the $20-24$-year-old group with $11 \%$ of females infected as compared to $7 \%$ of males. Due to the gender-based and economic inequalities present in many marriages and sexual relationships, women, especially girls, may find it difficult to communicate about HIV and negotiate condom use with their partners. Therefore, while knowledge of and access to HIV testing and other services are important, they are not sufficient to ensure HIV prevention. Girls must have strong social, health, and economic assets in order to gain more control within their sexual relationships.

Additional health risks - especially early pregnancy, unsafe abortion, and STIs — result from high levels of unprotected sex. In Zambia, among 15-19-year-old never-married girls, 31\% in urban settings and $45 \%$ in rural settings report have experienced sex. Overall, $12 \%$ of women 20-24 report first sex before age 15 and $54 \%$ before age 18. Married and unmarried sexually active adolescents need information, social support for informed decisionmaking, and access to services and technologies to effectively maintain their sexual and reproductive health. The common large age gaps between girls and their partners, which can result in financial dependencies, often puts these girls at social and economic disadvantages, which compromise their abilities to avoid violence and negotiate healthy sexual behaviour. In Zambia, there is a large unmet need for contraception among adolescents and young women; only $18 \%$ of nevermarried sexually active girls aged $15-19$, and $47 \%$ of young women $20-24$, have ever used a modern method of contraception.

Assets that prevent pregnancy among girls are critical because early motherhood is linked to school dropout, as well as social isolation and early marriage. According to the 2013-14 Zambia DHS, 29\% of all 15-19-year-olds have been pregnant or had a child (15\% among those who have never been married). Despite the high levels of risk for HIV and unwanted pregnancy, however, less than $50 \%$ of sexually active girls aged $15-19$ have had HIV tests in the last 12 months, and only $36 \%$ of sexually active, unmarried 15-19-year-olds used condoms at last sex.

The situation described above is a challenging one for adolescent girls in Zambia. Across a wide range of issues-education, social support, safety, and sexual and reproductive health-girls are at greater disadvantages compared to their male peers. The cumulative vulnerabilities confronting Zambian adolescent girls formed the basis for designing an intervention that a) focused on adolescent girls aged 10-19, b) delivered community-based interventions, and c) selected participants for the programme with the direct intention of capturing those girls who faced the most vulnerabilities described above.

${ }^{9}$ Bruce, Judith. 2007. "Girls left behind: Redirecting HIV interventions toward the most vulnerable." Transitions to Adulthood Brief no. 23. New York: Population Council. 


\section{Adolescent Girls Empowerment Programme - Intervention Summary}

\section{Theory of change}

The theory of change behind the Adolescent Girls Empowerment Programme (AGEP) posited that adolescent girls are empowered by building their social, health, and economic assets that they can then draw on to reduce vulnerabilities and expand opportunities. In the long term, they will then increase their likelihood of completing school, delaying sexual debut, and reducing risks of early marriages, unintended pregnancies, acquisition of HIV, and other possibly detrimental outcomes.

Figure 1. AGEP theory of change

\section{Asset Building Theory of Change}

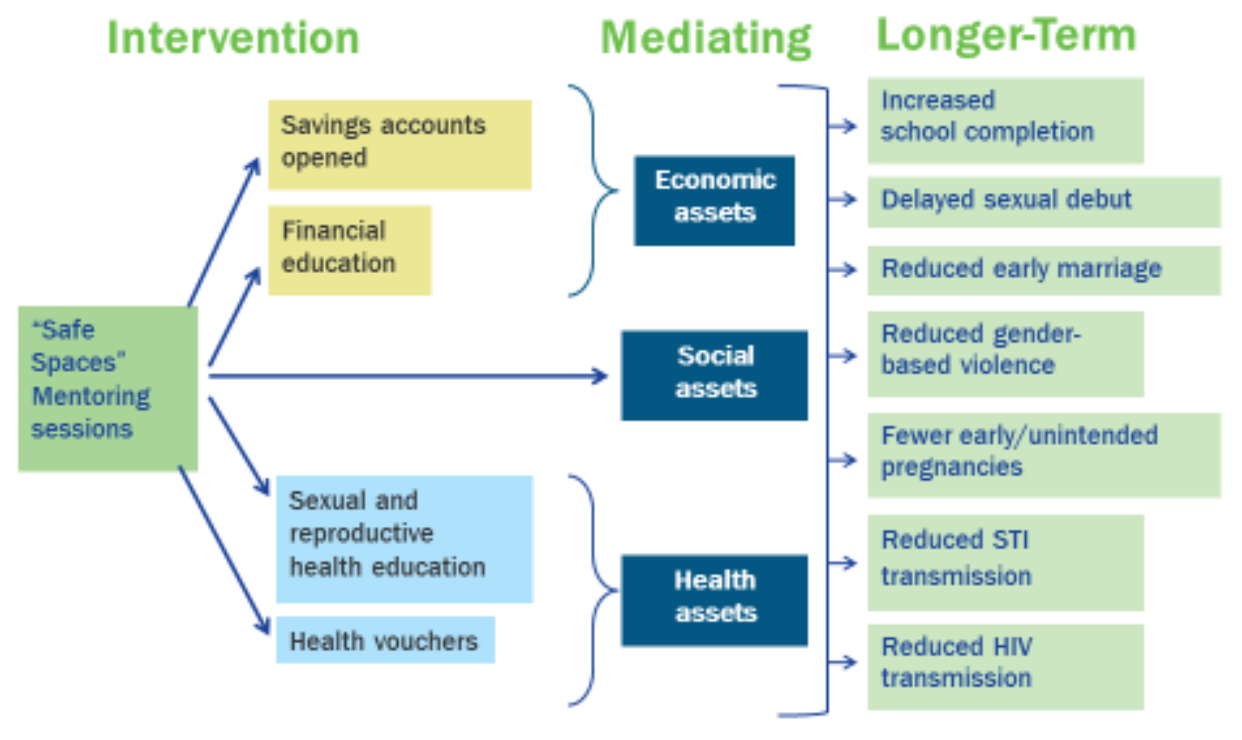

\section{AGEP overview}

To target those adolescent girls considered most at risk in Zambia, AGEP drew participants from lower-income backgrounds and living with multiple levels of vulnerability, e.g., physical and social isolation, without parents, in low-income households, and not attending school.10

AGEP was rolled out in 10 sites in four provinces in Zambia, five sites in urban and five sites in rural areas (see Figure 2). AGEP aimed to reach 1,000 girls per site, for a total of 10,000 girls who would be recruited into the programme. There were two urban sites in Lusaka province (Misisi/Chawama and Chipata/Chazanga); two rural sites (Mumbwa and Kapiri Mposhi) and one urban site (Kabwe) in Central Province; two urban sites (Ndola and Kitwe) and two rural sites (both in Masaiti) in Copperbelt Province; and one rural site (Solwezi) in Northwestern

${ }^{10}$ For more details on the selection of participants for AGEP please see the AGEP Study Protocol, the AGEP Baseline Report, and the Vulnerability Ranking Brief. 
Province. A site in a rural area contained multiple contiguous or proximal villages or chiefdoms, while in urban sites the programme was implemented within high-density housing compounds. The programme communities in urban areas were directly proximal to participating banks and health centres; in rural areas there were on average greater distances between households and health facilities and participating banks.

Figure 2. AGEP sites

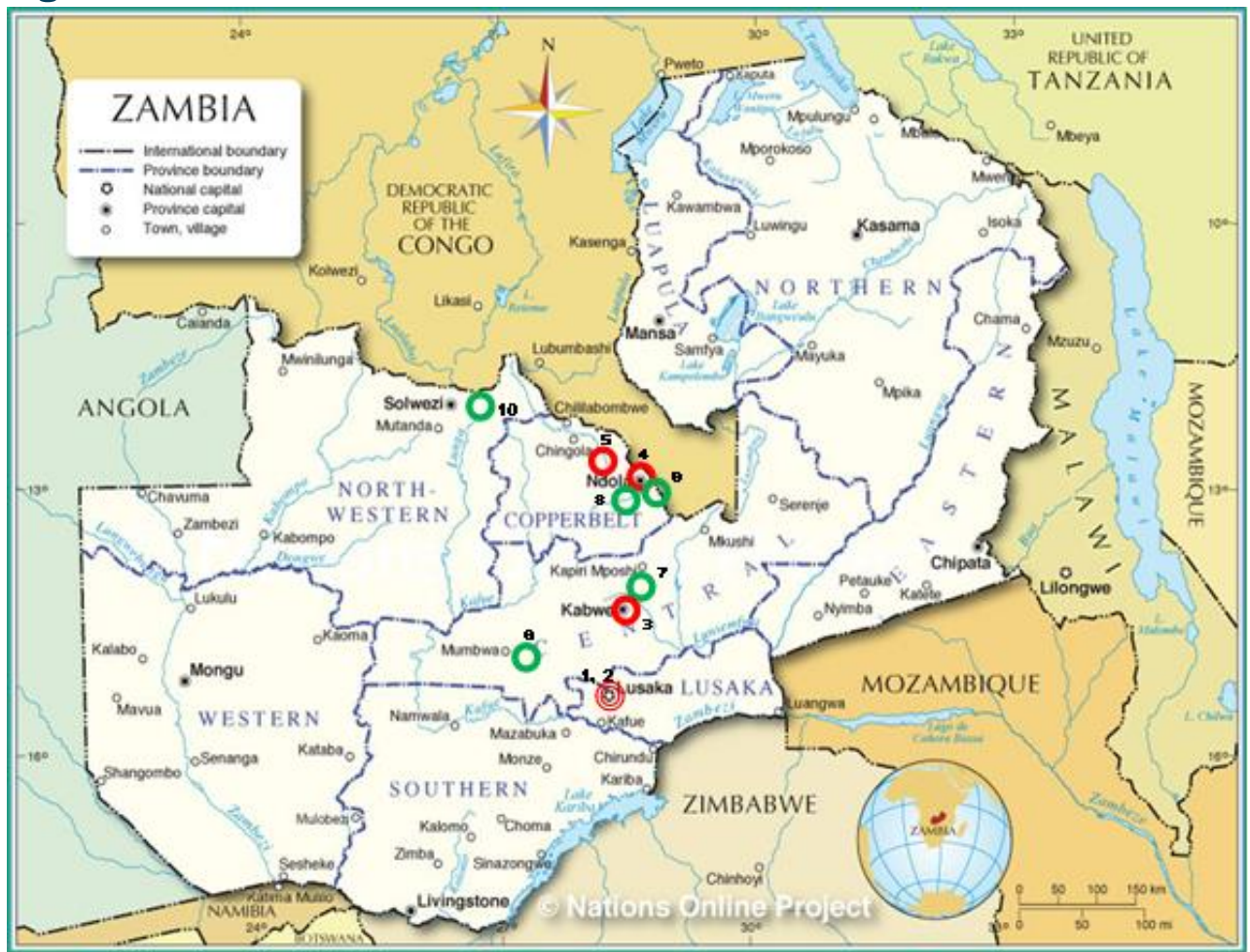

O One urban site

(O) Two urban sites

O One rural site

AGEP was implemented for two years in each site between 2013-16. Data were collected annually starting prior to the intervention in 2013. This report is a two-year follow-up after the intervention was completed (outlined by rectangle in Figure 3). ${ }^{11}$

Figure 3. AGEP programme and research timeline

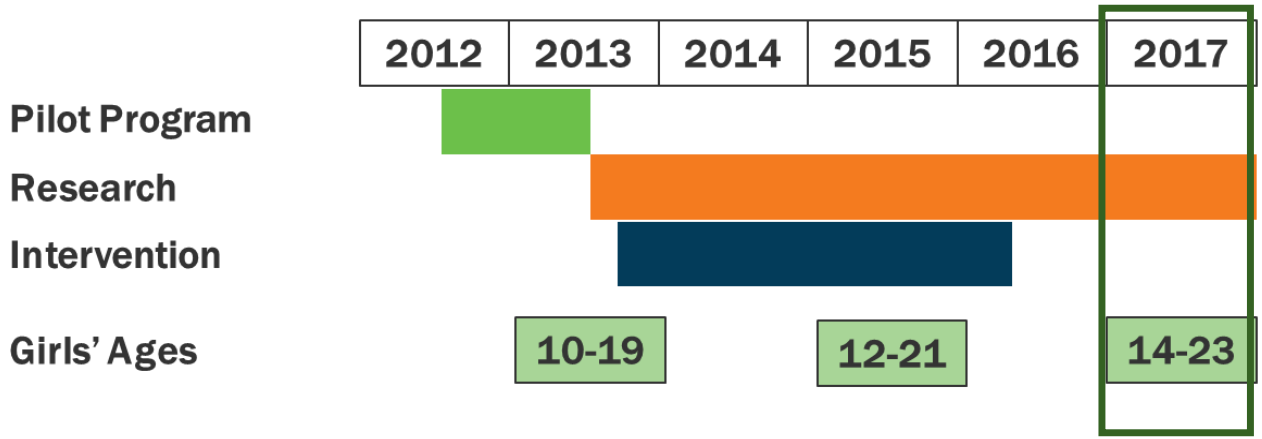

${ }^{11}$ For more information on the midline results, or the effect of the intervention just as the implementation was completed, please see the AGEP Research and Evaluation Midterm Technical Report. 


\section{Intervention Components}

Safe spaces: Safe spaces were weekly girls' group meetings, implemented in partnership with YWCA Zambia, in which 20 to 30 girls met with a mentor-a young woman from their community who was hired and trained-for short training sessions on a variety of topics as well as an opportunity to discuss together their experiences in the past week. AGEP developed three curricula ${ }^{12}$ used in the safe space meetings: 1) a health and life-skills curriculum, 2) a financial education curriculum, and 3 ) a nutrition curriculum ${ }^{13}$ for adolescent girls. Each trained mentor used the same curricula and was instructed on the order in which the sessions should be delivered to ensure standardisation across all groups. The groups met weekly over the course of two years. At the start of the programme, girls were assigned based on their ages to groups for 10-14-year-olds or 15-19-year-olds. The groups themselves chose the meeting date, time, and location based on when the girls were available and where in the community they deemed it safe to meet. See Annex A for the list of curriculum sessions.

Health vouchers: In partnership with the Ministry of Community Development, Mother and Child Health $\left(\mathrm{MCDMCH}^{14}\right)$, participants received a health voucher redeemable for a package of general wellness and sexual and reproductive health services at partner public and private healthcare providers. During the weekly meetings, mentors taught the girls about the voucher services and informed them of participating clinics where the voucher could be used. For private and NGO providers, payment was made on a "fee-for-service" basis with pre-approved reimbursement rates, whereas for the public facilities incentives for each service were paid to the District Community Health Offices ( $\mathrm{DCHO}$ ) and then distributed among the district health offices and the clinics in previously agreed-upon percentages.

Savings accounts: The Population Council worked in partnership with the National Savings and Credit Bank (Natsave) and Making Cents International to develop the Girls Dream savings accounts for AGEP girls. The Natsave accounts had very low minimum opening balances of ZMW 2.5 (US \$0.50) and any amount could be deposited or withdrawn with no fee. Mentors of girls opening savings accounts were trained by AGEP staff in the savings accounts features, and in turn the mentors conducted orientation sessions with the girls and their co-signatories prior to account opening, to instruct them how to use the accounts and begin the accountopening process. A field trip to the branch was also organized for girls and their co-signatories to complete the account-opening process. At the time the project began, there were approximately 32 Natsave branches throughout Zambia, predominantly located in urban areas.

\footnotetext{
12 http://www.popcouncil.org/uploads/pdfs/2013PGY_HealthLifeSkills_AGEP.pdf http://www.popcouncil.org/uploads/pdfs/2013PGY_FinancialEducation_AGEP.pdf http://www.popcouncil.org/uploads/pdfs/2014PGY_AGEP-NutritionEduc.pdf

${ }^{13}$ Half of all mentors in each site, stratified by arm, were randomly selected to be trained on and implement the nutritional curriculum in their safe space groups. This embedded sub-study assessed the impact of nutritional education integrated into the safe spaces curriculum on anaemia, dietary diversity, and anthropometric growth of adolescent girls and their children. A summary of the findings is available in this brief (https://www.popcouncil.org/uploads/pdfs/2018PGY_AGEP-NutritionBrief.pdf)

${ }^{14}$ Since the intervention, the Mother and Child Health unit has moved to the Ministry of Health and the current ministry is now called the Ministry of Community Development and Social Welfare.
} 


\section{AGEP - Research and Evaluation}

The ultimate objective of the AGEP evaluation was to conduct a rigorous assessment of the impact of the programme on the trajectories of girls' lives in their adolescent years and beyond. This translates to assessing whether AGEP improved mediating factors, i.e., the knowledge, assets, and skills girls possessed, as well as their longer-term demographic, reproductive, and health outcomes. The AGEP evaluation focused on vulnerable adolescent girls, aged 10-19 in 2013 as they aged to $14-23$ in 2017 . The midline evaluation, based on data collected in 2015, was published in 2016 and focused largely on whether the first step of the theory of change-i.e., empowering girls via building social, health, and economic assets-was confirmed ${ }^{15}$. This endline report presents the final impact of the programme two years after the intervention was completed while also reflecting on the mid- and long-term effects on the mediating factors.

The baseline or Round 1 survey began in July of 2013 prior to implementation at the programme sites. Subsequent interviews with adolescents were conducted annually between 2014-17. HIV and HSV-2 testing was conducted among adolescents aged 15 years and older at Rounds 1, 3, and 5. Anaemia testing among adolescents aged 15 years and older was added in 2015 and was conducted yearly through 2017.

\section{Study Design}

In order to assess the effect of only the safe spaces, as well as the added effect of the "add-on components," AGEP was implemented in three versions across randomised study arms: Arm 1 included safe spaces only, Arm 2 included safe spaces and the health voucher, and Arm 3 included safe spaces, the health voucher, and the savings account (Table 1). Arm 4 was a control in which there were no intervention activities. 


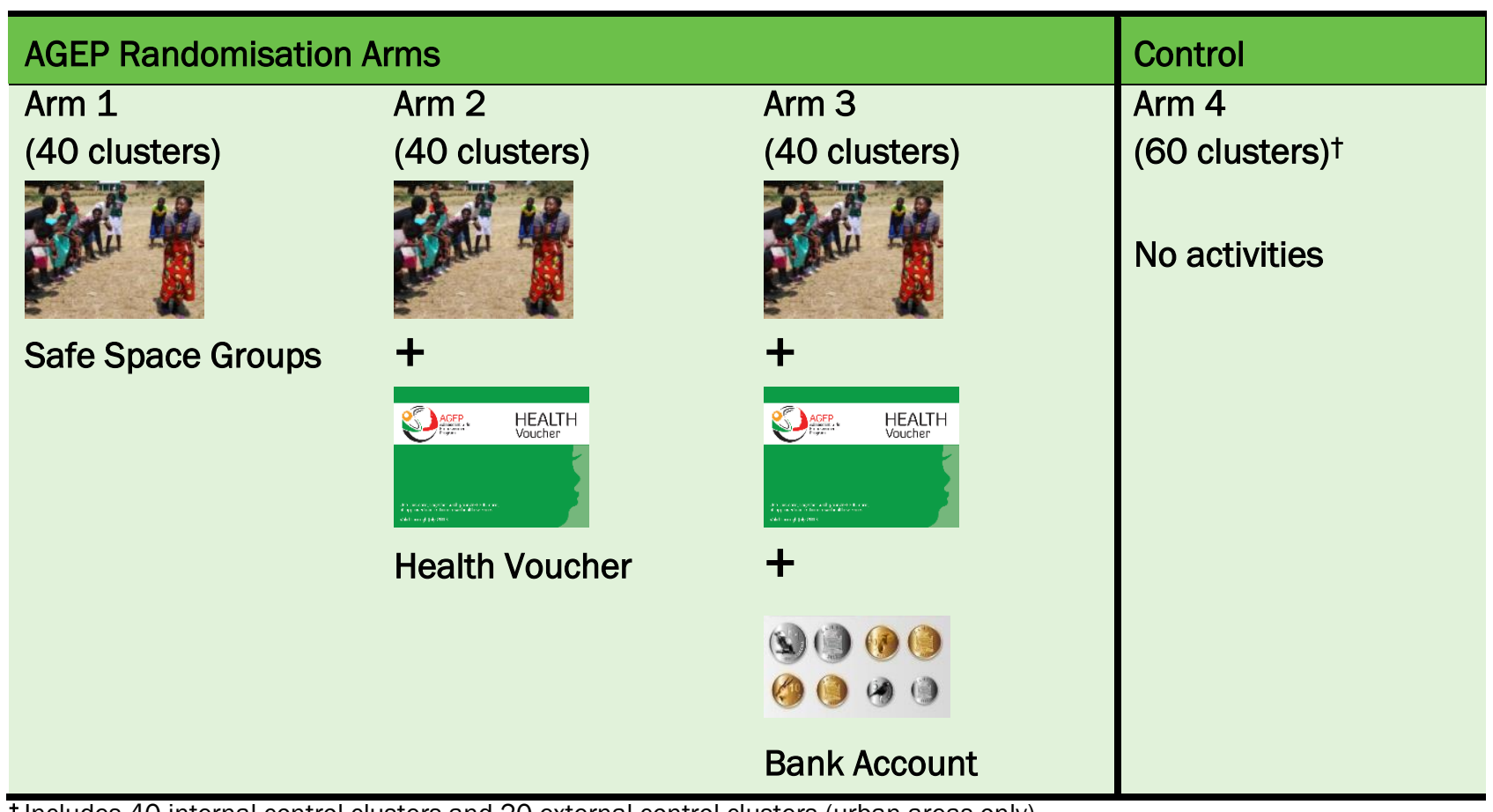

† Includes 40 internal control clusters and 20 external control clusters (urban areas only).

A randomised cluster design was implemented to rigorously assess the impact of AGEP, as well as to assess the impact of each of its core components. Clusters in each site were randomised at a public lottery to receive different combinations of AGEP components. Sample size calculations determined that 30 clusters for each of the three study arms, with a minimum of 20 girls per cluster by the end of the evaluation, were needed in order to ensure that probability of significant differences between groups was high. Therefore, there were 120 programme clusters (40 per arm, 4 per arm for each of the 10 sites), and 40 additional control clusters (4 for each of the 10 sites). Clusters were delineated by Census Supervisory Areas (CSAs) as specified by the Zambia Central Statistical Office (CSO). CSAs contained approximately 750 households in urban areas and 300 households in rural areas.

Selection of girls: The adolescent girls who were invited to participate in AGEP were selected from the household listings. A vulnerability indicator was constructed and girls ranked by their vulnerability scores. Those with the highest levels of vulnerability in each AGEP site were selected for the programme. Girls residing in boarding schools or mentally disabled were excluded, while all girls with physical disabilities were automatically invited. From that list of girls to be invited to the programme, 27 girls per CSA were randomly selected for the research sample. The only additional exclusion criteria were: a) one girl per household to increase the heterogeneity of the sample, and b) already being married at the start of the programme to increase the likelihood of observing transitions such as school dropout, start of sexual activity, and motherhood. ${ }^{16}$

\footnotetext{
${ }^{16}$ See the technical brief "Methodology: Reaching the Most Vulnerable Adolescent Girls" for more details on the vulnerability indicator (http://www.popcouncil.org/uploads/pdfs/2016PGY_AGEP-Vulnerability_brief.pdf)
} 


\section{Adolescent Survey}

The adolescent survey instruments were intended to measure changes in attitudes, behaviours, transition status, social assets, and cognitive skills that might occur over time related to education, sexual behaviour, marriage, sexual and gender-based violence, gender attitudes, self-efficacy, financial literacy, and savings behaviour-as well as a range of background and socio-demographic measures. The questionnaires were translated into the most common local languages spoken in the study sites. Surveys were implemented by electronic data capture using Samsung Galaxy tablets. Computer-Assisted Personal Interviewing (CAPI) was used for questions that were nonsensitive. CAPI is a process of data capture in which the interviewer reads the question from a computer screen and enters the participant's response directly into a handheld or tablet device. For sensitive questions, Audio Computer-Assisted Self-Interviewing (ACASI) was used. With ACASI the respondent listens on headphones to pre-recorded questions and response categories while simultaneously reading (if the participant is literate and desires to do so) the question on the tablet screen. The participant enters a response by touching a colour-coded number or option as specified in the audio script and on the tablet screen. ACASI maximises confidentiality and privacy of response, since no one can hear or see the question being read, nor the response option selected. In addition, height and weight measurements were taken from the survey respondents as well as their children up to 60 months old. Finally, biological markers for HIV and HSV-2 were collected from adolescents aged 15 and older in Round 1 (2013), Round 3 (2015), and Round 5 (2017). Anaemia testing for adolescents aged 15 and above, and their children 6-59 months old, was added in Rounds 3, 4, and 5. All biological specimens were collected at the households or in private spaces in the communities in cases where confidential interviewing and testing could not be done at homes.

\section{Programme Monitoring Data}

All programme data were carefully monitored and stored on a cloud-based MIS platform available to the programme and research teams. Mentors collected safe-spaces attendance data using Open Data Kit (ODK) on smart phones where at each meeting they recorded the date, session covered, and girls who were in attendance.

\section{Statistical Analysis and Evaluation Assessment}

To assess balance across the treatment and control samples that were interviewed, we estimated the mean and 95\% confidence intervals for the following variables measured at baseline: study sites, girls' ages, school status, grade attainment, literacy, numeracy, nonverbal cognitive skills, vulnerability, parents' living and co-residence status, parents' school attainment, and household wealth. We also estimated Pearson chi-square tests for categorical variables and linear regressions for continuous variables. To descriptively explore changes in outcomes, we estimated the mean and 95\% confidence intervals for all outcome variables measured at baseline and at Round 5 .

The primary analysis focused on the impact of the "intent-to-treat" (ITT), that is, the impact on girls who were invited to participate in AGEP regardless of their actual participation in the programme. We used a difference-in-differences (DID) approach with girl-level fixed effects to 
estimate the impact of the ITT on outcomes that were measured at both baseline and Round 5 , which means that we compared the average differences between baseline and endline within each study arm. A secondary analysis focused on the "treatment-on-the-treated" (TOT), as not all girls who were invited actually participated in the programme, and girls who did participate did so at different levels. The TOT analysis was conducted as a two-stage instrumental-variable (IV) estimation, which takes into account observable and unobservable differences between girls who participated and those who did not. In the first stage of the estimation, we used the randomised invitation to participate in AGEP (the ITT) as the instrumental variable to predict attendance to at least half (52 meetings) of the total girls' group meetings. For both the ITT and the TOT, we estimated models for all three programme arms combined and compared to the control arm. We also estimated models with separate indicators for each programme arm compared to the control arm.

In addition to the two-stage instrumental variable estimation, we estimated average treatment effects (ATEs) using propensity score matching (PSM). In the PSM approach girls who attended at least 52 meetings were compared with girls in the control arm that had the same or closest predicted probabilities of participation based on observed baseline characteristics. It is important to note that the PSM approach does not account for selection bias from unobserved characteristics that are likely to affect participation in the programme such as girls' motivation and parental support.

After conducting the primary and secondary analyses, we tested whether the programme had different impacts across sub-groups of girls. For both the ITT and the TOT analyses, we reestimated the regressions including interaction terms with the following characteristics of interest: urban versus rural, older (15-19) versus younger (10-14) baseline age cohorts, highest versus lower vulnerability quintiles, and poorest versus less poor household wealth quintiles so that we could see if having one of those characteristics shaped how the programme impacted girls in that group.

All regressions controlled for girls' age at last birthday and were estimated with robust standard errors accounting for clustering at the CSA level. ATES with PSM were estimated with robust standard errors. All statistical analysis was conducted using Stata 15.1. ${ }^{17}$

\section{Qualitative Data}

Complimentary qualitative research was conducted in 2015 and included 144 in-depth interviews with girls from each of the four study arms, mentors, parents and other community stakeholders. This component of the study aimed to further investigate some of the perceived programme impacts and better understand potential pathways to change. The results are not presented here although they are available in a standalone report ${ }^{18}$. Some of the qualitative findings were in line with the conclusions, although much does not confirm the quantitative findings. There are multiple reasons for this including small sample sizes in the qualitative

\footnotetext{
${ }^{17}$ An economic evaluation was conducted at midline that made use of detailed costing data on the implementation of each component of the intervention, as well as the costs to the mentors, girls, health facilities, and financial service providers for participation. In the Midline Technical Report the methodology and results were carefully laid out. As those costs have not changed between based and midline, and given the nature of the results, there was no need to update the economic evaluation for the endline.

18 http://www.popcouncil.org/uploads/pdfs/2016PGY_AGEP_QualEvalReport.pdf
} 
data, perceived effects of the respondents as compared to actual effects measured in the survey, and looking at effects for an individual versus across the whole sample. (See Appendix $B$ for more detailed reflections on the qualitative data).

\section{Limitations}

While the overall study design is quite rigorous, there are a few limitations that weaken the quality of the data and its ability to interpret how transitions are shaped for vulnerable adolescent girls in Zambia. First, taking a random sample for interviews at endline might have biased the sample and reduced power in ways that we are unable to detect. Second, it is possible that the timeline for viewing effects is longer than the AGEP cohort was followed and if we followed the entire sample into adulthood we would see differences between arms that are currently undetectable. However, that was not possible because of funding constraints. Finally, we did not collect data on household or community indicators, including norms on gender equity and violence, which may prevent us from understanding additional contextual facilitators and barriers to change. 


\section{AGEP Endline Results}

The AGEP endline evaluation report focuses on three main questions: 1) whether or not the changes in social, health, and economic assets (that are the mediating factors) that were observed at midline were sustained; 2) whether there new impacts observed in the social, health, and economic asset indicators; and 3) whether the intervention resulted in any longerterm change on education or demographic outcomes, and if so, for which girls. This endline report will provide a general overview on key indicators. The full set of detailed tables is located in Appendix $\mathrm{C}$ and includes the results from the ITT estimates, the TOT estimates from the twostage IV approach, the ATEs estimates from the PSM approach, as well as interactions with age, urban/rural location, girls' vulnerability, and household economic status.

The baseline sample had 4,661 girls evenly spread across the four study arms, of whom 89\% were re-interviewed in Round 3. In Round 5 the target sample was reduced to a sub-sample of 3,772 girls randomly drawn from girls who had completed Round 3, $82 \%$ of these girls were reinterviewed in Round 5.19 Follow up rates were similar across study arms, and baseline characteristics of the Round 5 sample were largely balanced across programme and control arms.

\section{Participation in Safe Spaces}

Understanding levels of programme participation is important for the presentation of programme impacts as different analyses account for how many sessions girls participated in. Girls' levels of programme participation were assessed from the baseline sample using three categories: never attended, attended less than 52 meetings, and attended 52 or more meetings; where 52 meetings represented roughly half of the number of possible sessions. As noted in Table 2, just over a quarter of girls invited to the programme never joined a safe spaces group; just under $50 \%$ of girls joined a group, but participated in less than half of the sessions, while approximately $30 \%$ participated in more than half the group sessions.

Table 2. Programme uptake (among baseline research sample in programme arms)

\begin{tabular}{|l|l|l|}
\hline & Sample & $\%$ \\
\hline Invited, never attended & 921 & 26.2 \\
\hline Invited, attended <52 meetings & 1,559 & 44.4 \\
\hline Invited, attended 52+ meetings & 1,035 & 29.4 \\
\hline
\end{tabular}

The mean number of sessions attended was roughly the same by study arm (see Table 3); hence, programme arm assignment or the added components of the intervention did not affect programme participation.

\footnotetext{
19 The reduction of the sample was due to budget constraints, largely caused by the devaluation of the British pound in 2016. The R5 target sample was $81 \%$ of the baseline sample $(3,772$ out of 4,661$)$. In addition, the external controls were dropped.
} 
Table 3. Descriptive statistics of meetings attended by baseline research sample in programme arms, by arm

\begin{tabular}{|l|l|l|l|l|}
\hline & $\begin{array}{l}\text { Sample } \\
\text { N }\end{array}$ & Mean & Min & Max \\
\hline $\begin{array}{l}\text { Arm 1 - } \\
\text { Safe spaces only }\end{array}$ & 1,186 & 33.6 & 0 & 106 \\
\hline $\begin{array}{l}\text { Arm 2 - Safe spaces + } \\
\text { health voucher }\end{array}$ & 1,169 & 32.6 & 0 & 113 \\
\hline $\begin{array}{l}\text { Arm 3 - Safe spaces + } \\
\text { health voucher + savings } \\
\text { account }\end{array}$ & 1,160 & 32.1 & 0 & 107 \\
\hline All arms & 3,515 & 32.8 & 0 & 113 \\
\hline
\end{tabular}

It is important to note that while overall survey response rates over the five rounds were the same for programme and control arms, the sub-sample of girls in programme arms that were re-interviewed in Round 5 had somewhat higher participation levels than those observed among the full baseline sample in programme arms: $34.6 \%$ of the girls in programme arms reinterviewed in Round 5 had attended at least 52 meetings, and the mean number of meetings attended among this sub-sample was 37.1. This suggests that, within the programme arms, girls who were more committed to the programme were more likely to have been re-interviewed at endline.

An analysis ${ }^{20}$ of who was more likely to participate showed that girls who were younger, living in rural areas, in school, and the biological daughters of the heads of households tended to participate in more session on average. ${ }^{21}$

\section{AGEP Mid- and Long-Term Impact on Social, Health, and Economic Assets}

Social assets: In the evaluation of AGEP, two key measures of empowerment via social asset building were measured-social safety nets and self-efficacy. At midline-which measured the impact immediately at the completion of the two-year intervention-girls in the three intervention arms were more likely than girls in the control arm to have a place in the community where they could meet other girls their age apart from their home and school $47 \%$ v. 38\%), however, there were no effects on self-efficacy, meaning that girls in the programme arms were no more likely than control girls to believe in their ability to accomplish tasks or achieve their goals.

Two years post-programme, there was no longer a difference between programme and control arm girls (54\% v. $52 \%$ ) vis-à-vis social safety nets, suggesting that the public spaces within communities that were created for girls by the programme were no longer available to them. There were no differences on this measure by any of the sub-groups of the sample

${ }^{20}$ Multivariate probit analysis

${ }^{21}$ Austrian, Karen, Paul C. Hewett, Erica Soler-Hampejsek, Fiammetta Bozzani, Jere R. Behrman, and Jean Digitale. 2016. Adolescent Girls Empowerment Programme: Research and Evaluation Mid-Term Technical Report. Lusaka, Zambia: Population Council. 
(older/younger, urban/rural, higher/lower vulnerability, or higher/lower household economic status). However, on self-efficacy, an effect in Round 5 did appear, with a statistically significant difference between the programme arms and the control arm (7.6 v. 7.3 on a 10point scale). A further analysis by arm and by age shows that this difference was driven by the older girls in the full programme package arm, reaching up to a two-point difference on a 10point scale. One potential explanation for this latent effect is that as girls grew older, the depth of life experiences in which they could apply the learnings and skills built from AGEP increased (especially for those with savings accounts), and therefore their beliefs in their abilities were concretised and became measurable.

Gender norms and acceptability of spousal violence: At the midline evaluation there was no effect of AGEP on either gender norms-which measured adolescent girls' attitudes on gender roles in adolescence-or acceptability of intimate partner violence (IPV) as measured by five items asking if it was acceptable for a husband to beat his wife in certain scenarios (i.e., refusing him sex, burning food, neglecting the children, etc.). The two-year follow-up showed that these norms and attitudes were still unchanged by the AGEP interventions. Overall, there was little change over time-in any arm-for these measures. For the seven items used to measure positive gender attitudes, the mean score was approximately 5 on a seven-point scale - at baseline, midline and endline. There was little variation between younger and older girls, as well as between urban and rural girls. The trend was similar for the acceptability of IPV. At baseline, only $38 \%$ of girls reported that IPV was not acceptable in any scenario. This percentage was the same at both midline and endline, indicating that these gender attitudes and views on violence are ingrained from an early age and do not change much throughout adolescence, regardless of exposure to an empowerment programme that addressed this issue with the participants. With IPV however, there were some variations within the segment subsamples, with younger girls and rural girls becoming somewhat more tolerant of IPV over the study period, yet little change over time among older and urban girls.

Health Assets: The two main health assets measured in the AGEP evaluation were sexual and reproductive health (SRH) knowledge and HIV knowledge. Both scales were made up of 11 questions. The SRH scale reflected largely contraceptive and fertility knowledge and the HIV scale was made up of a range of items on modes of HIV transmission and prevention. At midline there was an increase in SRH knowledge among girls in the programme arms relative to the control girls (see Table 4), however there was no difference in the increase in HIV knowledge between the two groups (8.2 for programme and control arms). It is important to note that overall, SRH knowledge was very low at baseline, and while it increased over the four years, it still remained low at endline, approximately the equivalent of learning about two new methods of contraception over that period, indicating room for further education on these topics. The girls who showed the largest gains in SRH knowledge were the older girls who actively participated, again, perhaps as they got older and engaged with the topic of contraceptives in reality as opposed to only in a lesson, the knowledge that they had gained through AGEP "stuck." There was no difference in impact for girls based on where they lived or their vulnerability or household economic status. 


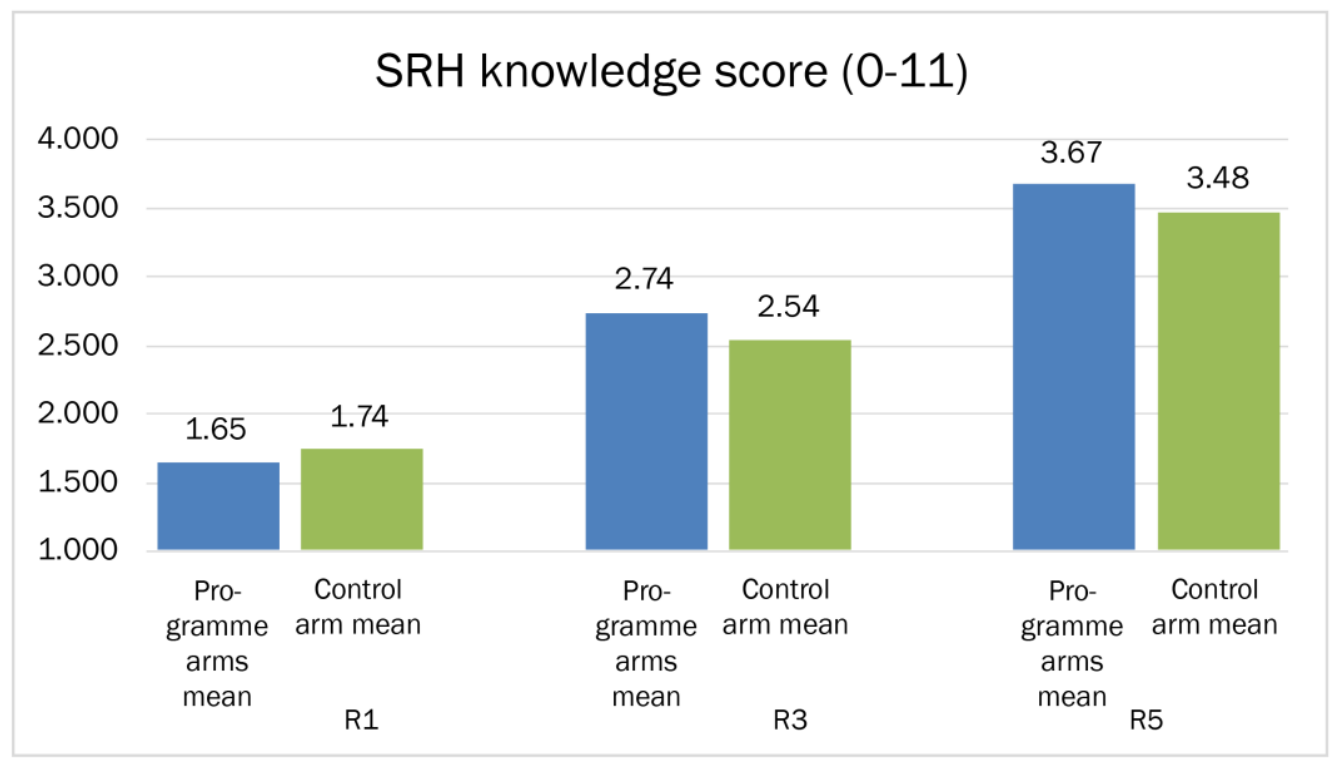

Economic assets: The two main economic asset indicators measured were the score on a ninepoint financial literacy scale and savings behaviour in the past year. The higher a score on the financial literacy scale meant that girls had more knowledge and skills of sound personal money management (budgeting, financial goal setting, etc.) and financial services. At midline, AGEP had a positive increase on financial literacy for all girls in the programme arms, and that increase was stronger for girls in the full programme arm, and even stronger for those who actively participated in the safe spaces sessions and had opened savings accounts (TOT analysis). At endline, the overall effect on financial literacy for all programme arms had washed out, meaning that overall, girls who had been in arms with financial education training scored the same as those who had not. However, a marginally significant effect remained for those who had opened savings accounts (a one-point increase over the control group), suggesting that having a savings account helped girls retain financial literacy. Regarding savings behaviour, a similar pattern to the positive effect on financial literacy at midline was present for girls who had saved in the past year as well. However, that effect remained at endline, with programme arm girls being 7 percentage points more likely to save than girls in the control. That percentage increased to 19 for girls who had actively participated in the safe spaces groups and 34 for those who actively participated and had opened savings accounts. The longterm effects for financial literacy and savings behaviour together suggest that a) AGEP was able to positively increase savings activity in the longer term, b) increases in financial literacy in the short/medium term had positive effects on savings behaviour in the long term, regardless of if the difference financial literacy knowledge "stuck," and 3) having formal savings accounts catalysed positive savings behaviour, both formal and informal.

Overall, on the mediating factors, the theory of change only partially held up. While there were some midterm improvements-namely on health knowledge and economic skills and behaviour-there were other assets that were not impacted, specifically gender norms and selfefficacy. For the most part the mediating factors that were impacted at midline remained improved two years later, although perhaps not at high enough levels, or enough of a diversity of assets, to translate into impact onto longer-term outcomes. 


\section{AGEP Long-Term Impact on Demographic, Reproductive, and Health Outcomes}

Experience of violence: Overall, neither at midline nor at endline did the AGEP intervention reduce girls' experience of physical or sexual violence. What should be noted, as seen in Table 5 , is that experience of both kinds of violence was high at baseline, and steadily increased over the course of the study such that two-thirds of girls by ages 14-23 had experienced physical violence and half of girls by ages 15-23 had experienced sexual violence. Older girls in urban areas were most likely to experience sexual violence, but there was no difference on vulnerability or household economic status. These measures indicate that violence is endemic in these communities, and combined with the lack of reduction in inequitable norms or experience of violence shows that more than the AGEP intervention components will be needed to create change in these areas.

\section{Table 5. Experience of physical and sexual violence-all arms combined}

\begin{tabular}{|c|c|c|c|}
\hline & Baseline & Midline & Endline \\
\hline Physical Violence ${ }^{22}$ & $43 \%$ & $57 \%$ & $65 \%$ \\
\hline Sexual Violence 23 & $20 \%$ & $40 \%$ & $50 \%$ \\
\hline
\end{tabular}

Sexual behaviour: Overall, the AGEP intervention had little impact on either overall sexual activity, or sexual behaviour among those who were sexually active-at both midline and endline (see Table 6). This included contraceptive use, condom use, and the number of sexual partners.

\section{Table 6. Sexual behaviour}

\begin{tabular}{|l|ll|l|l|l|l|}
\hline & \multicolumn{3}{|l|}{ Baseline } & \multicolumn{2}{l|}{ Midline } & \multicolumn{2}{l|}{ Endline } \\
\hline & AGEP & Control & AGEP & Control & AGEP & Control \\
\hline $\begin{array}{l}\text { Ever used modern } \\
\text { contraception24 }\end{array}$ & $9 \%$ & $10 \%$ & $33 \%$ & $35 \%$ & $57 \%$ & $56 \%$ \\
\hline $\begin{array}{l}\text { Had two or more sexual } \\
\text { partners in last 12 months }\end{array}$ & $9 \%$ & $9 \%$ & $14 \%$ & $15 \%$ & $15 \%$ & $14 \%$ \\
\hline
\end{tabular}

At midline, girls who were sexually active at baseline were more likely to use a condom, but by endline that effect was no longer present, meaning that in the longer term, the AGEP programme did not have a positive influence on girls' safer sex behaviours. The one area of positive impact was on girls who were already sexually active at the start of the programme. Those girls were less likely to have had transactional sex-largely driven by their response to whether or not they had had sex in exchange for protection or a place to stay-and this effect

\footnotetext{
${ }^{22}$ Asked of girls 13 years old and above.

${ }^{23}$ Asked of girls 15 years old and above.

${ }^{24}$ Asked of girls 15 years old and above.

${ }^{25}$ Asked of girls 15 years old and above.
} 
was present at midline (10 percentage points less likely) and at endline ( 8 percentage points less likely), and higher for girls in urban areas. This effect is perhaps explainable, in the face of little effect on other dimensions of sexual behaviour, given the economic aspect of sexual relationships that this indicator addresses and the improvements in financial literacy and savings seen as result of the programme.

One area of mixed results is on sexual debut, with the ITT results indicating a negative effect, i.e., girls in the programme arms (84\%), particularly older girls in urban areas, were more likely to have ever had sex as compared to the control arms (78\%), but the PSM results showed no effect on sexual debut. Given that there was no effect on sexual debut in Rounds 2 through 4, we describe the effect on sexual debut as inconclusive.

Pregnancy and marriage: Counter to the initial hypothesis, participation in AGEP, as well as a modest change in some of the mediating factors, did not delay the timing of pregnancies or marriages for girls in the programme arms. Overall, 39\% of girls had given birth by the end of the two-year follow-up period and $28 \%$ of girls were married or living with their partner-and there was no significant difference between the programme and control arms. Interestingly, girls who scored higher on the vulnerability ranking were more likely to have been pregnant, although urban/rural location, age, or household economic status did not make a difference. None of these characteristics increased or lowered the likelihood of having ever been married. In the PSM analysis, girls were 9 percentage points less likely to have ever given birth or been married compared to their matched controls, suggesting that for a select group of girls who actively participated, AGEP did have a positive impact. However, as in our interpretation of the sexual behaviour results, we cannot be conclusive in these findings, nor be satisfied knowing that only a select, potentially biased group that was less vulnerable than the average participant benefited from the intervention.

HIV and HSV-226: Overall, HIV prevalence increased from $2.9 \%$ to $6.3 \%$ as the baseline sample increased from 15-19 to 19-23 years old. Prevalence in urban areas was higher, increasing from $3.8 \%$ to $7.5 \%$ as compared to $1.6 \%$ to $4.9 \%$ in rural areas. HIV incidence was 0.9 cases per 100 persons between 2013 to 2017 (0.93 in urban sites and 0.85 in rural sites). Overall, AGEP had no impact on HIV prevalence or incidence. HSV-2 prevalence increased from $7.2 \%$ to $17.6 \%$ to $26.1 \%$ between 2013 to 2017 for the same sample of girls. Interestingly, for HSV-2, prevalence was higher in rural areas as compared to urban areas, with the increase going from $7.0 \%$ to $19.6 \%$ to $29 \%$ in rural areas and from $7.5 \%$ to $15.9 \%$ to $23.6 \%$ in urban areas. HSV-2 incidence was 5.0 cases per 100 persons between 2013 to 2017 (6.0 in rural sites and 4.2 in urban sites). The impact of AGEP on HSV-2 prevalence was similar to sexual debut, with different results as per the different analyses, therefore we are not able to make conclusive determinations.

Interesting to note are the geographical variations, with Kabwe having consistently higher HIV and HSV-2 prevalence than the urban average, Lusaka being near the average, and the urban Copperbelt sites (Kitwe and Ndola) being below average. For the rural sites, the Copperbelt sites were above average (both Masaiti sites), Central rural sites were near the average, and

${ }^{26}$ A full paper on HIV and HSV-2 prevalence, incidence, and the factors associated with these outcomes is forthcoming. 
Solwezi in Northwestern Province was below average. This is important epidemiological data to have for future targeting of adolescent HIV programmes.

\section{Summary table of results}

\begin{tabular}{|c|c|c|c|c|c|}
\hline Mediating factors & $\begin{array}{l}\text { Change at } \\
\text { midline }\end{array}$ & $\begin{array}{l}\text { Change at } \\
\text { endline }\end{array}$ & $\begin{array}{l}\text { Stronger } \\
\text { effect for } \\
\text { rural/urban } \\
\text { girls?* }\end{array}$ & $\begin{array}{l}\text { Stronger } \\
\text { effect for } \\
\text { older/young } \\
\text { er girls?* }\end{array}$ & $\begin{array}{l}\text { Stronger } \\
\text { effect for } \\
\text { participating } \\
\text { girls?* }\end{array}$ \\
\hline Self-efficacy score & -- & $\checkmark$ & - & Older & Yes \\
\hline Has a safe space in community to meet with friends & $\checkmark$ & - & -- & -- & -- \\
\hline Financial literacy score & $\checkmark$ & - & - & Older & -- \\
\hline Saved money in the past year & $\checkmark$ & $\checkmark$ & Urban & Older & Yes \\
\hline SRH knowledge score & $\checkmark$ & $\checkmark$ & -- & Older & Yes \\
\hline HIV knowledge score & -- & - & -- & -- & -- \\
\hline Positive gender attitudes score & -- & - & - & - & - \\
\hline Non-acceptability of IPV & -- & - & -- & Older & -- \\
\hline \multicolumn{6}{|l|}{ Longer-Term Factors } \\
\hline Completed grade nine & -- & - & - & -- & -- \\
\hline Ever had sex & -- & $\sim$ & Rural & - & $\sim$ \\
\hline Ever been pregnant & -- & - & -- & -- & -- \\
\hline Ever been married & -- & - & -- & -- & $\sim$ \\
\hline Ever had transactional sex (if had sex at baseline) & $\checkmark$ & $\checkmark$ & Urban & -- & Yes \\
\hline Ever used modern contraception & -- & - & -- & -- & -- \\
\hline Ever experienced sexual violence & -- & - & Rural & Younger & -- \\
\hline HIV+ & -- & - & -- & -- & -- \\
\hline HSV-2+ & -- & $\sim$ & Rural & Younger & $\sim$ \\
\hline
\end{tabular}

$\checkmark=$ positive change (as hypothesised)

$x=$ negative change (opposite of what was hypothesised)

$--=$ no change/difference

$\sim=$ mixed results depending on analysis

* = at endline 
Overall, in reflecting on the theory of change, the hypothesis was that the AGEP interventions would lead to increased social, health, and economic assets, and those in turn would lead to longer-term education, fertility, and health improvements. The theory of change did not prove to be confirmed in two major elements: 1) there was positive change only on a subset of the mediating factors-largely the economic assets and some of the health assets, but not on most social assets-and with modest effect sizes; and 2) the changes that did take place in the mediating outcomes were not sufficient to lead to longer-term change. Therefore, overall, the pathways to change that were anticipated did not take place.

These results were shared with key policymakers, donors, civil society members, and implementing partners at the national Evidence for Impact Symposium in March 2018. Additional workshops have been held with implementers in Zambia to address how these findings can be used to adapt current and design new programmes for adolescents in Zambia. Thematic policy briefs that accompany this report were prepared and are available on the study website. ${ }^{27}$ The results have been presented and will continued be shared in global adolescent forums.

27 http://www.popcouncil.org/uploads/pdfs/2018PGY AGEP-SGBVBrief.pdf http://www.popcouncil.org/uploads/pdfs/2018PGY AGEP-NutritionBrief.pdf http://www.popcouncil.org/uploads/pdfs/2018PGY AGEP-HealthBrief.pdf http://www.popcouncil.org/uploads/pdfs/2018PGY AGEP-FinanceBrief.pdf 


\section{Conclusions}

The Adolescent Girls Empowerment Programme (AGEP) was a social, health, and economic asset-building programme targeting vulnerable adolescent girls aged 10-19 that was successfully implemented in four of the 10 provinces of Zambia from late 2013 to early 2016. In addition to the programme, a rigorous impact evaluation was embedded among 4,661 adolescent girls at baseline whose objective was to assess the mid-term and long-term impact of AGEP. A randomised cluster design with four study arms was implemented and the results of the study after two years of AGEP implementation, as well two years after the implementation was completed, are presented in this report.

At the end of the two-year programme, the following impacts were seen:

- Improved sexual and reproductive health knowledge

- Improved access to safe spaces in the community

- Improved financial literacy

- Improved savings behaviours

- Decreased transactional sex (for girls who were sexually active at the start)

Two years after the end of the programme, the following impacts were seen:

- Improved sexual and reproductive health knowledge

- Improved self-efficacy

- Improved savings behaviours

- Decreased transactional sex (for girls who were sexually active at the start)

There were no medium or long-term effects on:

- Pregnancy/birth

- Marriage

- Sexual debut, contraceptive use, condom use, multiple sexual partners

- Equitable gender attitudes

- Experience of physical or sexual violence

Therefore, while there were some changes for the programme participants in the medium and long term, it did not translate into longer-term effects on reproductive and demographic outcomes as hypothesised via the theory of change. While interpreting these results, it is important to remember that a) a large proportion of the girls invited to the programme did not participate and b) among those who did participate, only a sub-segment of them participated actively in the safe-spaces sessions. Knowing who is and is not participating in a programme meant that targeting vulnerable adolescent girls is important-both for programmatic implementation guidance and for interpretation of results. While for that active sub-segment of girls the programme did appear to have short- and long-term effects on a range of indicators, those effects were only for a relatively more-privileged set of girls. It is likely that in order to reach the most vulnerable segment of girls in any given community, the intervention would need to work at multiple levels of the community-including the household, the school, and the community level. This will no doubt be more complex, and hence more expensive, and this is important for policymakers, donors, and implementers to be aware of. 
One of the clearest and most consistent findings was in the economic asset-building component. The savings account catalysed positive savings behaviour-both formal and informal-and had positive effects on girls' self-efficacy. This provides an indication to programmes working with adolescent girls as to the feasibility and important impact of integrating financial literacy training and access to savings opportunities into more traditional health-related programming.

Overall, in looking forward to future programming for adolescents in Zambia, it is likely that interventions based on a combination of the asset-building theory of change outlined at the start of the study, combined with a more ecological model 28 to address the range of institutions and individuals influencing outcomes for adolescents, will provide stronger impacts across a range of adolescent well-being outcomes. Programmes that seek to improve health outcomes for a wide range of vulnerable adolescents need to address underlying economic and sociocultural constraints, for example through social cash transfers, educational support or social norms change campaigns, both to increase participation and to improve the likelihood that the programme will result in longer-term health changes.

\section{Recommendations for policymakers/implementers:}

1) The most vulnerable adolescent girls will likely not attend a safe spaces-only programme. While the safe spaces platform to building assets for girls can be leveraged to achieve longer-term change for girls on a range of well-being outcomes, it is likely that the most vulnerable are going to participate less, or not at all. Programme implementers must ensure that they have the systems and budgets in place to track who is, and is not, participating. They will need to include adaptations to their programmes to address the needs of those sub-segments of the population (e.g., out of school, economically most disadvantaged, those living apart from their parents) to allow for enrolment and active participation.

2) Acceptability and experience of sexual and gender-based violence (SGBV) among adolescent girls and young women in Zambia is alarmingly high; it will take a more holistic, community-level programme to address this. Sixty percent of girls think that violence is $\mathrm{OK}$ in certain circumstances and over half of girls ages 14-23 have already experienced sexual violence. Given that the AGEP intervention components, which all worked at the level of the girls and had no impact on either of these sets of indicators, future programmes that aim to reduce SGBV among adolescents should address attitudes and norms around violence at the household, school, and community levels, as well as work with adolescents directly.

3) Economic barriers will influence adolescent programmes-even those that are health oriented-and need to be addressed in adolescent programming. Household economic barriers exist, especially among the most vulnerable that will prevent participation, as well as prevent desired health outcomes from being achieved. Programmes should consider education support to those who are at risk of school-dropout or are out-of- 
school but likely to return to school. Social cash transfers may have the potential to alleviate some of the economic stress of the household, freeing up girls to participate in programmes. It may also mitigate some of the economic reasons that drive transactional sex, school dropout, and/or early marriage. Individual economic barriers, especially for older girls, also exist. Retaining an economic component to the programme, financial literacy, and savings, will help address these issues. For older girls, it is likely that additional activities that promote income-generation will need to be added to programmes.

\section{Recommendations for donors/researchers:}

1) More analysis can be done with the AGEP data set. There is a wealth of data available that can be used to look at the impact of the programme on additional outcomes and for various subsets of the adolescent girls cohort. The data are available at the Adolescent Data Hub. 29

2) Many evidence gaps remain, and as this is a complex issue with multiple interdependent outcomes, more research is needed. More work should be done to deliver and evaluate programmes that aim to address long-term health outcomes for adolescents, that take a multi-level approach, including simultaneous work with communities, households, and adolescents themselves.

3) More longitudinal research on adolescents is needed. The results between midline and endline did change-including some emerging results-and therefore there is value in following cohorts of adolescents through to early adulthood to understand the effect of interventions in early and mid adolescence on later adolescence and early adulthood. This may include effects on the transition to the workforce, quality of marital relationships, health and education outcomes for adolescents' children, etc. In addition, more longitudinal research, that combines data from these different levels, will help to understand the multiple factors and context that shape adolescent transitions into adulthood.

4) More research and learning from work on cash transfers are needed. More research is needed in Zambia to evaluate programmes that combine providing asset-building for adolescents with cash incentives at the household level. There is promising evidence coming out of Kenya ${ }^{30}$ that suggests that that combination, implemented in early adolescence, may have more long-term success. In addition, The Transfer Project has been conducting work in Zambia, ${ }^{31}$ and other countries in sub-Saharan Africa, ${ }^{32}$ that could provide useful insights into the role of social-protection cash-transfer programmes. The potential of combining general cash transfers with additional programming for adolescents remains a promising area that needs more research.

\footnotetext{
$29 \mathrm{https}: / /$ doi.org/10.7910/DVN/CFIUC6

30 https://www.popcouncil.org/uploads/pdfs/2018PGY_AGI-K_MidlineReport.pdf

$31 \mathrm{https}: / /$ transfer.cpc.unc.edu/countries-2/zambia/

32 https://transfer.cpc.unc.edu/countries-2/
} 
The AGEP evaluation is an important contribution to the understanding of adolescent transitions and interventions in Zambia. The rigorous and long-term approach provides a level of certainty, attribution, and conclusions that are unparalleled in Zambia. It is our hope that this evaluation will contribute to the improvement of current programmes, and the development of new programmes and funding strategies. The data show that early pregnancy, violence, and HIV are still very pressing issues for adolescents in Zambia and evidence should be used to design and implement the programmes most likely to improve adolescent girls' lives going forward. 
HEALTH AND LIFE SKILLS CURRICULUM

Introductory Sessions

Session 1: What to Expect-Part 1

Session 2: What to Expect-Part 2

Session 3: Teamwork

Session 4: His and Hers (Gender Roles)

Session 5: Communication

Session 6: Self-Esteem

Session 7: Goal Identification-The Road of Life

Session 8: Goal Setting and Achieving

Session 9: My Relationships

\section{Reproductive Health}

Session 1: Life Cycle

Session 2: My Body Is Changing-Am I Normal?

Session 3: How Does Pregnancy Happen, Anyway?

Session 4: Preventing Unintended Pregnancy (Contraceptives)

Session 5: Reproductive Myths

Session 6: Sexual Desire

Session 7: Unsafe Abortion

Session 8: Abortion and Stigma

Session 9: Maternal Mortality

\section{Life Skills}

Session 1: I Have Healthy Relationships

Session 2: Reasons to Delay Sex

Session 3: Strategies for Delaying Sex

Session 4: Passive, Assertive, Aggressive

Session 5: Drugs, Alcohol, and Other Mind-Altering Substances

Session 6: Peer Pressure

Session 7: Making Good Decisions

Session 8: How to Communicate with Adults

Session 9: How to Communicate with a Partner

Session 10: Managing Stress, Anger, and Conflict

Session 11: Conflict Resolution and Problem-Solving Skills

HIV, AIDS, and STIs

Session 1: HIV and AIDS

Session 2: Myth or Fact?

Session 3: HIV Testing and Counseling

Session 4: Risky Behaviour

Session 5: The Relationship of STIs and HIV and AIDS

Session 6: Stigma and Discrimination in HIV-Positive People

\section{Gender and Gender-Based Violence}

Session 1: Sexual Exploitation

Session 2: How to Report and Avoid Cases of Sexual Violence

Session 3: Rape and Gender Violence

Session 4: Preventing Unwanted Advances

\section{Leadership}

Session 1: Leadership

Session 2: Community Service - Putting Leadership into Action 
Human Rights

Session 1: Human Rights and Children's Rights

Session 2: Sexual and Reproductive Health Rights

Session 3: HIV and AIDS and Human Rights

\section{FINANCIAL EDUCATION CURRICULUM}

\section{Dream Big}

Session 1: Dream Big!

\section{The Steps for Saving and Earning Money}

Session 2: Why Save?

Session 3: Choose a Savings Goal

Session 4: Make a Savings Plan

Session 5: Learning About Banks and Bank Accounts

Session 6: Exploring Options for Earning Money

Session 7: Girls' Money and the Risky Income Cycle

Session 8: Know the Difference Between Needs and Wants!

Session 9: Control Spending

Session 10: Think About the Future: Money In and Money Out

Session 11: Save Regularly

\section{Talk About Money}

Session 12: Save in a Safe Place

Session 13: Dealing with Setbacks in Saving

Session 14: Your Own Money vs. Someone Else's Money

Session 15: Talking About Money

Session 16: The DOs and DON'Ts of Talking About Money

Session 17: Resolving Conflicts About Money

Session 18: Role Play Resolving Conflicts

\section{Conclusion and Reflection}

Session 19: Our Journey to Good Money Management

\section{NUTRITION CURRICULUM}

Session 1: Nutrition Needs for Adolescent Girls

Session 2: The Role of Food in the Body

Session 3: Anaemia in Adolescent Girls

Session 4: Nutrition for Pregnant Adolescents (15-19 Only)

Session 5: Infant Feeding from Birth through Six Months (15-19 Only)

Session 6: Young Child Feeding and Growth Monitoring (15-19 Only) 


\section{Annex B: Qualitative Findings}

Note: The full qualitative report is available at http://www.popcouncil.org/uploads/pdfs/2016PGY_AGEP_QualEvalReport.pdf

The qualitative report provided some interesting insights into the perceived impacts of the programme, not only from the girls, but also those around them including mentors, parents, and other community stakeholders. Many of the qualitative respondents talked about positive behaviour change vis-à-vis less risky sexual behaviour, increased education, delayed pregnancy, and more. These were changes that girls reported experiencing themselves, as well as observed in the girls by their mentors and parents. However, these changes were not demonstrated through the quantitative evaluation, which should provoke thought over the differences between perceived impact and demonstrable change.

Another positive dimension of AGEP that was discussed was the impact that the programme had on the mentors themselves. Mentors reported gaining personal knowledge, skills, and a positive standing and place of respect within the community. These effects would not have been picked up by the quantitative survey because only girls were interviewed for that component of the study.

The qualitative report also provides some insights into some perceived tensions with the programme, that may have affected implementation and girls' ability to participate in the safe spaces groups. Issues raised in the qualitative data included allegations that the programme was affiliated with Satanism, that parents and community members feared that the programme perhaps encouraged promiscuity-specifically the SRH content of the curriculum-that girls felt unwelcome in their safe spaces group if they became pregnant during the course of the programme, that girls faced competing priorities that sometimes prevented them from attending safe spaces sessions and that there was some resentment among non-AGEP girls who were aware of the programme because they were not able to participate. All of these challenges are potential barriers to participation that implementers should take into consideration in the implementation of future programmes, and may also provide some explanations as to why some of the most vulnerable girls did not participate in AGEP. 
Annex C: Full Detailed Quantitative Results

The following Excel tables are available at:

http://www.popcouncil.org/uploads/pdfs/2018PGY AGEPEndlineReport AnnexC.xlsx

Table C1. Outcomes by arm: Raw means by arm at R1, R3, and R5

Table C2. Results Round 5: This includes the ITT, TOT, and PSM results for all key indicators at Round 5

Table C3. Results Round 5 by Arm: This includes the ITT and TOT results at Round 5 by arm

Table C4. Results Round 5 with location interaction: Compares the ITT and TOT results for urban v. rural samples

Table C5. Results Round 5 with location interaction: Compares the ITT and TOT results for older v. younger samples

Table C6. Results Round 5 with location interaction: Compares the ITT and TOT results for highest vulnerability girls v. lower vulnerability

Table C7. Results Round 5 with location interaction: Compares the ITT and TOT results for girls from poorest households v. less poor households 